\title{
Investigation of Tribological Properties of Two-Component Bidisperse Epoxy-Polyester Composite Materials for Its Use in the Friction Units of Means of Sea Transport
}

\author{
Andriy Buketov¹, Mykola Brailo1, Serhii Yakushchenko", Oleksandr Sapronov¹, Vasyl Vynar², \\ Oleh Bezbakh¹, Roman Negrutsa \\ 1 Department of Transport Technologies, Marine Engineering Faculty, Kherson State Maritime Academy, \\ 73003 Kherson, Ushakova Ave., 20, Ukraine \\ 2 Laboratory of Tribocorrosion and Corrosion Fatigue Materials, \\ Department of Physico-Chemical Methods of Corrosion Protection of Metals, \\ Karpenko Physico-Mechanical Institute of the NAS of Ukraine, \\ 79060 Lviv, Naukova St., 5, Ukraine \\ * Corresponding author, e-mail: yakushchenko.sv@gmail.com
}

Received: 19 September 2018, Accepted: 26 April 2019, Published online: 27 May 2019

\begin{abstract}
The tribological properties of complex polymeric materials, which include epoxy and polyester resins, two hardeners and two microdispersed fillers: mica-muscovite, copper (II) oxide, were investigated in the work. The results of the testing of specimens at dry friction and in the lubricant were analyzed. It is proved, that the antifriction properties of the composite depend on its composition, formation technology and testing conditions. It has been experimentally determined, that the material which was tested in the lubricating environment $-I_{m}=0.25-0.30 \mathrm{mg} / \mathrm{km}, f=0.03-0.04$, differs with the improved indexes of wear rate and friction coefficient. As a result of the analysis of investigated microsurfaces studied by optical and electron microscopy, the phase heterogeneity of the composite material system was identified. It contributes to the reduction of the running-in distance of the specimen, and indicates the uniform distribution of the filler particles on the surface, has been found. The elemental composition of the compound was determined, which indicates the direct involvement of fillers in the process of friction. A change in the ratio of atoms on the specimen surface before and after the test was found. The results of the study of the surface in the phase contrast mode correlate with the results of the data obtained by electron microscopy.
\end{abstract}

Keywords

epoxy-polyester composite, tribological properties, friction, disperse filler, electronic microscopy

\section{Introduction}

The modern shipbuilding industry is one of the largest consumers of synthetic polymeric materials. Areas of their application are diverse, and prospects of use cover a wide range [1-4]. Polymers are used to make ship hulls and body structures, to create details of ship mechanisms, instruments and equipment, to protect metal from corrosion, decoration of premises, their heat, sound and vibration isolation, and others. Due to the use of such materials, the technical and operational characteristics of marine transport equipment are significantly improved, their reliability and durability are increased, and the length and complexity of construction is reduced. It should be noted that polymer composite materials (PCM) have been used in the manufacture of important shipbuilding components, operated under conditions of aggressive environments, high temperature fluctuations, and tropical humidity. One of examples is manufacturing of stern tube bearing shells from polymer [5]. At the same time, it is important today to find ways to reduce the wear of friction units of machines of existing structures. The priority is the creation of parts and mechanisms that differ in wear resistance, the ability to work at high specific pressure, high speeds and temperatures [6]. This is an important aspect of the further development of sea and river transport. The replacing of existing designs with PCMs is technically and economically feasible, as the composite material (CM), 
unlike metal or other parts, is characterized by low cost and high performance. The reliability of parts and mechanisms increases in the application of CM, which primarily affects their trouble-free operation. This also reduces the need for maintenance and increases the inter-repair period, which is important for the operation of transport vehicles. Therefore, the development and application of polymer composite materials of tribotechnical purposes on the marine and river transport, which differ with high reliability, durability and ability to control properties, is the actual task of the modern transport industry.

Today, the high level of dynamic loads at the friction units of marine and river transport and the need of their work for a long time without special service lead to the replacement of traditional materials with polymers [7-9]. Epoxy and polyester resins are one of the common components used to form PCM. The material formed on the basis of these binders is distinguished by improved physical and mechanical, thermophysical properties, as well as the simplicity of the formation and relative cheapness. Duleba et al. (Slovak Republic) [10], Datsyuk et al. (Germany) [11], Brusentseva et al. (Russia) [12], Agrawal et al. (India) [13], Şahin and De Baets (Turkey, Belgium) [14] used an epoxy resin as the basis for the manufacture of composites. Separately, He et al. (USA) [15], Lin et al. (China) [16], Lavoratti et al. (Brazil) [17] studied the properties of polymeric materials on the basis of unsaturated polyester resins of various natures. The scientists in their works highlighted the advantages and disadvantages of using these binders for the production of polymeric CM. However, it should be mentioned that the study of a matrix containing both epoxy and polyester resin in the same binder is absent. It has been found out that the combination of these components makes it possible to develop composite material with predetermined improved performance. At the same time, it is known [18] that improvement of the antifriction properties of CM occurs by adding dispersed fillers to their composition during the formation. The development of filled polymeric composites provides high indexes of tribological properties of friction units and increases their lifetime. Among these, it is important to investigate surfaces of specimens after the test during the development of $\mathrm{CM}$ with improved antifriction properties. This allows us to detect physical and chemical phenomena and processes in the field of contact of bodies during the friction, which directly affect the indices of characteristics of the investigated composite $[19,20]$. Obtaining the results of the study of the surfaces of friction and analyzing of the received data will enable the formation of composite materials with predetermined properties and improved performance. In turn, it will provide the uninterrupted run of parts and mechanisms of marine transport for a long period of operation.

\section{Materials and methods}

The previously developed matrix, which contains the following components, was used in the work for the investigation of tribological properties:

1. Epoxy resin ED-20 ( $\mathrm{q}=100$ pts.wt.).

2. Ortho-phthalic dicyclopentadiene unsaturated pre-accelerated polyester resin ENYDYNE H 68372 TAE $-\mathrm{q}=10$ pts.wt. (the content is indicated on 100 weight parts of epoxy resin), which has an inhibitor to prevent instant polymerization (gel time $\mathrm{t}=20-24$ min). It should be noted, that during the copolymerization reaction of the composition of unsaturated polyesters with non-limiting monomer compounds in the presence of initiators a significant amount of heat is released; therefore, the reaction is exothermic.

3 . The cold curing hardener polyethylene polyamine (TU 6-05-241-202-78) - $\mathrm{q}=10$ pts.wt. (the content is indicated on 100 weight parts of epoxy resin).

4. The initiator for polyester resins Butanox-M50 $\mathrm{q}=1.5$ pts.wt. (the content is indicated on 100 weight parts of polyester resin), which is a peroxide of methyl ethyl ketone and contains a low amount of water and a minimum amount of polar compounds in comparison with ethylene glycol.

The tribological properties of developed epoxy CM with increased physical and mechanical properties were investigated in this work. The composites were formed on the basis of a matrix, which contained a two-component bidispersion filler of the following composition.

The material was filled with fractions of fractionated micromica of brand MC-20-80 $(\mathrm{d}=20-40 \mu \mathrm{m})$ and copper oxide $\mathrm{CuO}(\mathrm{d}=8-10 \mu \mathrm{m})$ at a ratio of $30: 60$, respectively.

For the fractionated micromica of series "Standard" (ISO 3262-12:2001) with grains $d=20-40 \mu \mathrm{m}$, the mineral composition is mica-muscovite. The chemical composition according to ISO 3262-12:2001 is silicon oxide $\left(\mathrm{SiO}_{2}\right)$ - 44-50\%, aluminum oxide $\left(\mathrm{Al}_{2} \mathrm{O}_{3}\right)-27-35 \%$, iron oxide $\left(\mathrm{Fe}_{2} \mathrm{O}_{3}\right)-<5 \%$, magnesium oxide $(\mathrm{MgO})-<2 \%$, potassium oxide $\left(\mathrm{K}_{2} \mathrm{O}\right)->8 \%$, and water-soluble salts $-<0.2 \%$.

Copper oxide (copper (II) oxide) is a binary inorganic compound with the chemical formula $\mathrm{CuO}$, amphoteric oxide of divalent cuprum with particle size $d=8-10 \mu \mathrm{m}$. 
The tribological properties of the materials were investigated on the test machine of serial production 2070 SMT1 , according to the block on ring technique and the method of GOST 23.224-86.

The wear rate was determined by Eq. (1):

$$
I_{m}=\Delta m / \Delta L
$$

where $\Delta m-$ is the difference in specimen mass before and after friction, $\mathrm{mg} ; \Delta L$ is sliding distance, $\mathrm{km}$.

The coefficient of friction was calculated in accordance with GOST 11629-75, by Eq. (2):

$$
f=M /(F \cdot r)
$$

where $M$ is the arithmetic mean of the friction moment, $\mathrm{H} \cdot \mathrm{m} ; \mathrm{F}$ is a load on the block, $\mathrm{H}$; and $r$ is a radius of a metal counterbody (shoulder), $\mathrm{m}$.

The disk (counterbody) was made of steel 45, heattreated to hardness 45-48 NRS and with surface roughness $\mathrm{R}_{\mathrm{a}}=0.16-0.32 \mu \mathrm{m}$.

The study was conducted in dry friction conditions and under influence of lubricant environment at specific load $\mathrm{p}=1 \mathrm{MPa}$ and slip velocity $v=1.0 \mathrm{~m} / \mathrm{s}$. The slipping of the specimens during the tests was $10,000 \mathrm{~m}$.

The contact temperature of the investigated specimens was determined using a thermocouple, "chromel-copel", the signal from which was recorded by the measuring apparatus. The thermocouple was placed at a distance of $l=2 \mathrm{~mm}$ from the contact area of the specimen with the counterbody.

The test modes were selected according to the conditions of use of the CM.

The reproducibility of the results is ensured by the repeatability of the experiments.

A study of one material, according to predetermined filler content, was conducted using 5 specimens. The verification of the reproducibility of the experiments was obtained by the Cochran test for the statistical processing of the obtained results of the experiment. The verification of the experimental results using the Cochran test for a fixed probability of $95 \%$ confirmed the reproducibility of the experiments. The error of the experiment did not exceed $4-6 \%$.

The mass of the specimens was determined by weighing with analytical scales, with an accuracy of $\pm 0.001 \mathrm{~g}$.

The structure of the CM after friction was investigated on a XJL-17AT metallographic microscope, which was equipped with a Levenhuk C310 NG (3.2 MegaPixels) camera. The image enlargement range varied from $\times 100$ to $\times 1,600$ times. Directly in the work, the specimens were examined with an increase of $\times 100$ and $\times 200$ times. For the processing of digital images, Levenhuk ToupView software was used.

The surface of the composites was studied by electron microscopy, using a ZEISS EVO 40XVP scanning electron microscope equipped with an INCA Energy 350 $\mathrm{X}$-ray microanalysis system with a $10-\mathrm{mm}$ lithium detector. This provided a resolution of $133 \mathrm{eV}$, an impurity detection sensitivity of $0.01 \%$, and an analysis locality from $1 \mu \mathrm{m}$ on standard specimens and up to $0.1 \mu \mathrm{m}$ on films. To ensure a good electrical contact between nonconductive materials and dielectrics, a pellicle of gold was sprayed into several atomic layers on their surfaces.

The materials were solidified according to the following regimen: forming of the specimens and their holding over time $t=12.0 \pm 0.1 \mathrm{~h}$ at temperature $T=293 \pm 2 \mathrm{~K}$, heating at a speed of $u=3 \mathrm{~K} / \mathrm{min}$ to temperature $T=393 \pm 2 \mathrm{~K}$, keeping the specimens at a given temperature during the time $t=2.0 \pm 0.05 \mathrm{~h}$, slowly cooling to a temperature of $T=293 \pm 2 \mathrm{~K}$. In order to stabilize the structural processes in the matrix, the specimens were kept in air during time $t=24 \mathrm{~h}$ at temperature $T=293 \pm 2 \mathrm{~K}$, followed by conduction of the experimental tests.

\section{Results and discussion}

All stages of the process of formation and friction of specimens were analyzed in detail to create PCM with predetermined antifriction properties. At the initial stage, the investigations of tribological properties of $\mathrm{CM}$ on the basis of a combined epoxy-polyester matrix with two fillers of different dispersion were conducted. The specimens were tested under different conditions: dry friction (without lubrication) and in the lubricating environment. As a result of the experiment, the improvement in the value of the coefficient of friction was seen, which leads to a decrease in energy losses during the test of this material. It has also been determined that under conditions of the CM test in the lubricant environment, the temperature indices in the contact area of the moving joint surfaces were reduced. This suggests that when testing a composite in a lubricant, the pair counterbody-specimen is separated by a layer of liquid material. It reduces the friction between the touching surfaces and carries off the heat from them.

It should be noted that when testing the CM in lubrication, temperature stability was observed in the friction region (Fig. 1, curve 4, Table 1). The amplitude of the contact temperature values fluctuated within the limits of $T=294-295 \mathrm{~K}$. This can be explained by the formation of a film from the lubricant, which is formed on tangent 


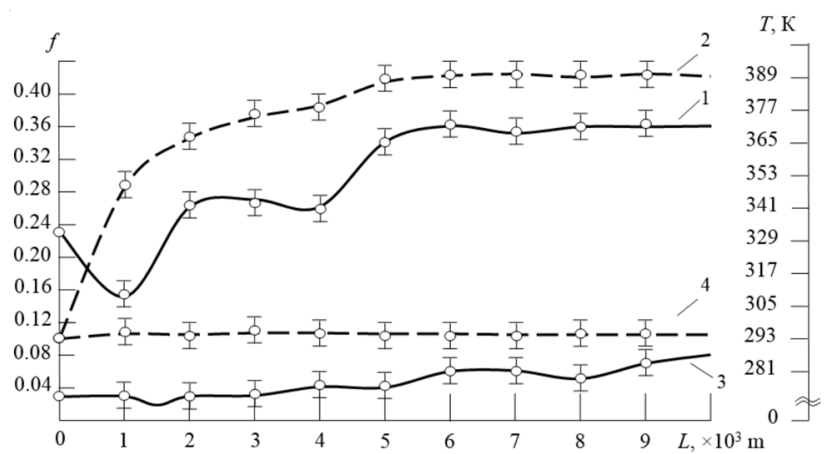

Fig. 1 The dependence of the friction coefficient and contact temperature on the distance of composite materials testing: 1 - coefficient of friction during testing without the use of a liquid;

2 - contact temperature during testing without the use of a liquid; 3 - coefficient of friction during testing in the lubricant environment; 4 - contact temperature during testing in the lubricant environment.

Table 1 Tribological properties of CM

\begin{tabular}{lcc}
\hline Parameters & \multicolumn{2}{c}{ Testing of CM in conditions of } \\
dry friction & $\begin{array}{c}\text { lubricant } \\
\text { environment }\end{array}$ \\
\hline Moment $M, \mathrm{H} \cdot \mathrm{m}$ & $1.72-1.78$ & $0.15-0.22$ \\
Coefficient of friction, $f$ & $0.33-0.35$ & $0.03-0.04$ \\
Contact temperature $T, \mathrm{~K}$ & $366-369$ & $294-295$ \\
Running-in distance $L, \mathrm{~m}$ & $5500-6000$ & $1500-2000$ \\
Wear rate $I_{m}, \mathrm{mg} / \mathrm{km}$ & $4.3-5.3$ & $0.25-0.30$ \\
\hline
\end{tabular}

lines of friction pair and provides shielding for the penetration of heat into the surface layers of the composite.

At the same time, at the initial stage of the study of the tribopair in the lubricant environment, a decrease of the coefficient of friction was observed at the passage of the distance $L=1250-1500 \mathrm{~m}$ (Fig. 1, curve 3). It is obvious that this is due to a decrease in the surface roughness of the composite during the test at specific pressure $p=1 \mathrm{MPa}$. In this case, the running-in distance is $L=1500-2000 \mathrm{~m}$, the coefficient of friction is $f=0.03-0.04$. It should also be noted that the wear rate of the $\mathrm{CM}$, when tested in the lubricant and dry friction, is significantly different and makes $I_{m}=0.25-$ $0.30 \mathrm{mg} / \mathrm{km}$ compared to $I_{m}=4.3-5.3 \mathrm{mg} / \mathrm{km}$, respectively.

In our opinion, mixed friction was observed on the running-in distance $6000-10,000 \mathrm{~m}$. As a result of partial extrusion of lubricants in the places of greatest irregularities the contact of surfaces of friction occurs, resulting the destruction of the boundary film under the dominant display of the boundary and semi-dry modes of lubrication. This leads in places to the direct contact of the solid with a counterbody, which is accompanied by phenomena of adhesion in friction, seizure, scoring on the surface of the CM. These phenomena complicate the process of running-in of the friction pair, as the products of tribodestruction form on the surface of the composite micro particles, which can act as abrasive. An increase in the indices of the tribological properties of the $\mathrm{CM}$, which was tested in the lubricating environment (Fig. 1, curve 3) at the above indicated interval of the friction distance, is the confirmation.

An analysis of the images and fractograms of the studied surfaces was conducted for the confirmation of the theory of increasing of the friction coefficient indices on the running-in distance $L=6000-10,000 \mathrm{~m}$ as a result of increasing of the surface roughness of the composite material due to the phenomena of adhesion in friction, seizure, scoring. A comparison of the specimen images before (Fig. 2a) and after the test (Fig. 2b and c) was held at the first stage of the experiment. It should be noted, that the tested specimens were manufactured under the same technological conditions and have the same content of the components. It is noticeable in Fig. 2a that the area of friction of CM before the test has an uneven surface. There are pronounced prints from the air outlet on the surface of the composite, which is caused by the technological parameters of the forming process. It should also be taking into account that amphoteric oxide of bivalent copper was used as one of the fillers. Complex physicalchemical and physical processes occur when forming such a composition. They include the restoration of surface layers, saturation of metal surfaces with atoms, which are parts of the polymer, additional structure formation of polymer.

At the first stage of running-in of the test specimen, the mechanical contact of the counterbody with the microirregularities of the surface with the initial roughness was observed. Since, as noted above, a relatively low specific load was used when performing the experiment, then for a period of time, at which the parameters of the initial surface roughness of the $\mathrm{CM}$ change and the operational roughness is formed, a decreasing of the coefficients of
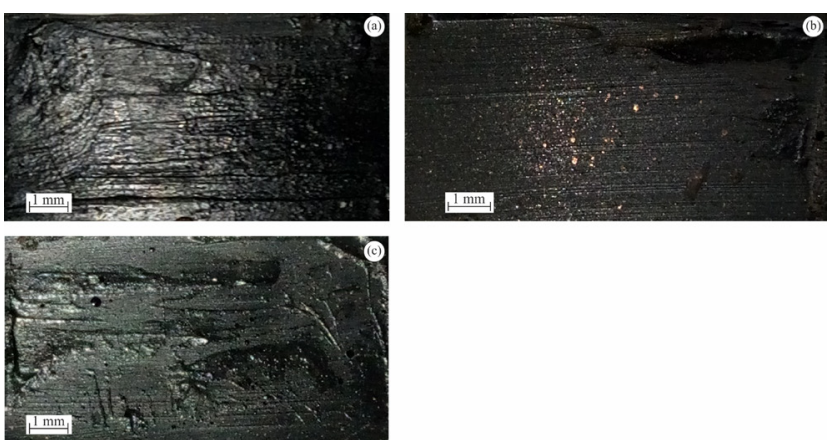

Fig. 2 Images of specimens surfaces with an increase of $\times 2$ times: (a) in the initial state; (b) after dry friction test; (c) after testing in the lubricant environment 
friction was observed. The tribotechnical indexes become stable after running-in of the specimen and determination of operational roughness, which is confirmed by the results of the investigation shown in Fig. 1.

As it is known, the loading of fillers into a polymer matrix leads to the formation of phase heterogeneity in the system, which helps on faster running-in. The simultaneous influence of the properties of the individual components of the composite material is provided, which results in an increase in the total effect due to such interaction. The dispersed particles of the fillers on the surface of the $\mathrm{CM}$ were found, analyzing the images after the dry friction test and independently in the lubricant (Fig. 2 b and c). Solid inclusions are uniformly distributed in the composite and, therefore, take load and then transmit it to the matrix. The matrix is a damper in this case, while reducing the contact pressure on the projections of the friction surfaces. Also, noted the presence of friction tracks on specimens after the test in both cases. According to their visual inspection it can be asserted that the wear rate at testing without lubrication is higher than that of friction in the lubricating environment, which is confirmed experimentally (Table 1). It should be noted that the actual area of contact at dry friction is bigger than at lubricated friction. However, in both cases, an optimal microrelief of surfaces is created and wear-resistant secondary structures are formed.

Look in more detail the microrelief of the working surfaces when tested in lubrication. The fractograms of the investigated specimens with an increase of $\times 100$ and $\times 200$ times are shown in Fig 3. A marked heterogeneity of the matrix was revealed during the analysis of fractures of the CM after the friction in the lubricant. The inclusion of the fillers is evenly distributed in the friction region of the specimen (Fig. 3 a). Bright elements (1 in Fig. 3), which are obviously dispersed particles of mica, are noticeable in the images of the surface microstructure,
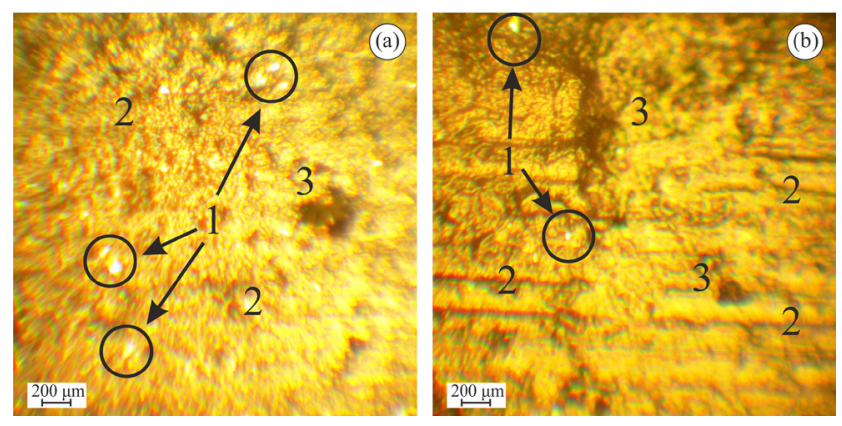

Fig. 3 The images of the surfaces of the investigated specimens obtained with a metallographic microscope, with an increase of $\times 100$ and $\times 200$ times after testing in the lubricant environmen with an increase of $\times 100$ times. As it is known from the standard of the manufacturer [21], mica-muscovite $\mathrm{KAl}_{2}\left[(\mathrm{OH}, \mathrm{F})_{2} \mathrm{AlSi}_{3} \mathrm{O}_{10}\right]$ has a refractive index of $n=1.58$, so it reflects light well. This confirms the influence of the particles of fillers on the process of friction.

There are expressed friction lines (see 2 in Fig. 3) in the images of the microstructure of the wear surfaces as a result of the test of antifriction properties of the CM. The depth of the immersion of the furrows is insignificant, so we can state the hardness of the surface layer, which reduces the wear rate of the composite during the testing in the lubricant. Also, the damages of microstructure, which arose as a result of scoring and transfer of material of the matrix (3 in Fig. 3), were discovered during the analysis of images. The presence of these surface damages explains the assumption of increasing the friction coefficient at the running-in distance $L=6000-10,000 \mathrm{~m}$ when tested in a lubricant environment. This leads to an increase of the surface roughness of the investigated material, which adversely affects the tribological properties of the friction pair.

The next stage of the investigation of the composite, tested in the lubricant, was conducted on a scanning electron microscope (SEM). The use of SEM gives the ability to observe the topography of a solid with an increase and depth of field, which far exceeds the corresponding indices of optical microscopes.

The investigated surface is irradiated by a thin-focused electron beam in a scanning electron microscope, which can be expanded in a raster on the surface of the specimen. Secondary electrons, backscattered electrons, characteristic X-rays, Auger electrons and photons of different energies arise as a result of the interaction of the electron beam with the investigated specimen. They are used to determine the characteristics of the object (elemental composition, topography of the surface, crystalline orientation, etc.).

As it is known, composites are dielectric materials and they are difficult to test using SEM. Absorbed electrons accumulate when an electron probe hits the surface of the dielectric, due to the absence of drain of the charge, which leads to the appearance of charged areas. These charged areas may in irregular way reject the initial beam in the next scan, which results in an error in obtaining the veracious information of the experiment. In addition, the presence of surface charge significantly changes the secondary electron emission. This effect is eliminated by application of the conductive coating on the surface of the 
specimen, in particular by sputtering gold. The criterion for choosing gold as a material for sputtering is to get the maximum amount of secondary electrons. Based on the consideration of the physical aspects of secondary electrons emission, it was recommended to form a layer with a thickness of 8-10 nm when sputtering, which provides maximum electron emission. The microanalysis was conducted in two ways - spot and scanning along the friction surface along the chosen direction in the range of enlargement of $\times 50-\times 500$ times.

It should be noted that the higher average atomic number of the element ensures the formation of a greater number of secondary scattering electrons from the specimen. This leads to the formation of a vivid image for such materials, which makes it possible to qualitatively determine the location of elements on the surface of the CM at the first stage of research [22].

In the analysis of the microstructure of the surfaces of the original specimen (Fig. 4) and CM, which was tested with dry friction (Fig. 5), it was found that the system is heterogeneous, the dispersed fillers are evenly distributed in the volume of the composite. This confirms the participation of mica particles and $\mathrm{CuO}$ in the friction. The processes of wear of the CM were observed on the image of surface of the specimen with dry friction. There are processes of destruction and allocation of material from the surface of the matrix, which arose as a result of seizure and scoring. As to the nature of their distribution, they are not located directly around disperse particles. This makes it possible to assert the effectiveness of the interphase interaction of matrix fillers in the formation of $\mathrm{CM}$ and their strong adhesion in accordance with the molecular

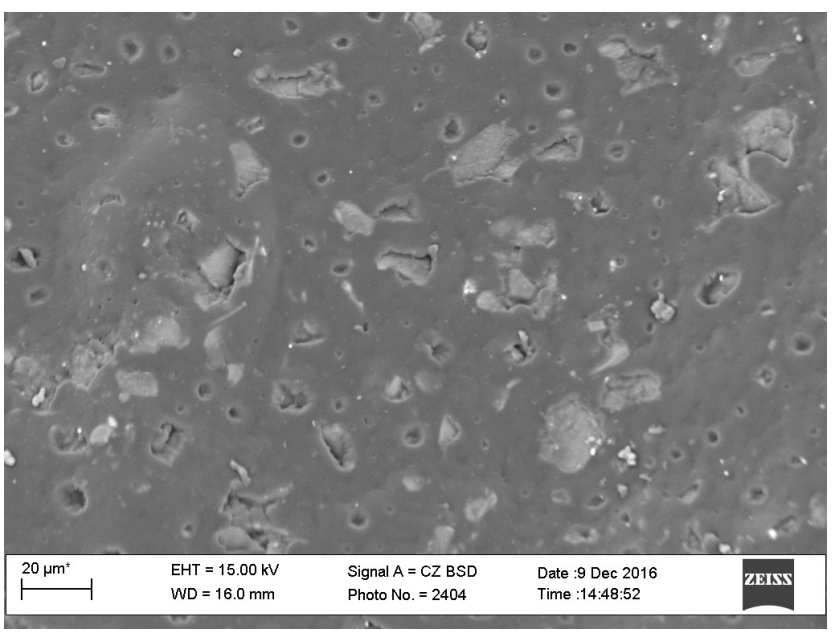

Fig. 4 The microstructure of the surface of the specimen in the initial state, obtained by means of a scanning electron microscope in the range of magnification $\times 500$ times

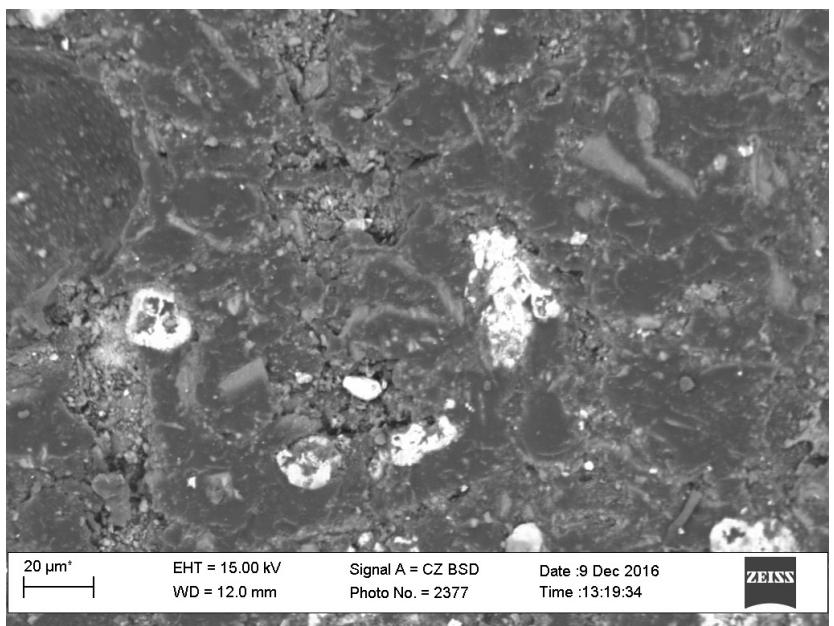

Fig. 5 The microstructure of the friction surface of the specimen after being tested with dry friction, obtained by means of a scanning electron microscope in the range of magnification $\times 500$ times

theory of adhesion. According to this theory, the presence of chemically active, polar or polarizable groups on surfaces should necessary be to ensure a high adhesion strength of the contacting surfaces of the matrix and disperse fillers. At the same time, spherical defects are present in the image of the initial surface of the specimen (Fig. 4), which are formed during incomplete degassing of the composition during the polymerization.

The analysis of the surface microstructures of the specimens, tested without lubrication (Fig. 5) and in the lubrication (Fig. 6), allows to affirm that the brightest areas of the microstructure of the surface can be attributed to the element of copper, and the darker ones - to the carbon (corresponding to their atomic numbers).

Analyzing the results of the investigation of the specimen microsurface after testing in the lubricant in magnification $\times 50-\times 500$ times (Fig. 6), one can note the following. Mica plates and bivalent copper oxide particles are evenly distributed in the composite, forming a heterogeneous system with a polymer matrix, and take direct part in the friction process. The destruction and isolation of the material from the surface layer of the CM, damage of the investigated contact plane in the form of wide and deep furrows in the direction of slipping were revealed. The spherical craters formed by polymerization of the matrix due to the air insertion, are filled with friction products. The deterioration of the compound decreases (see Fig. 6 d) compared to the surface of the composite material during the test without lubrication (Fig. 5). The obtained results of the analysis of the microrelief images of the working surface of the specimen in accordance with the chosen conditions are consistent with the nature of 


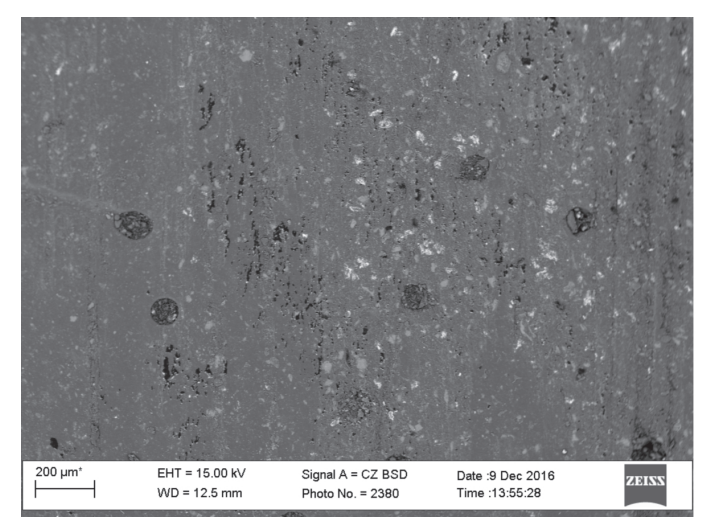

a) $\times 50$

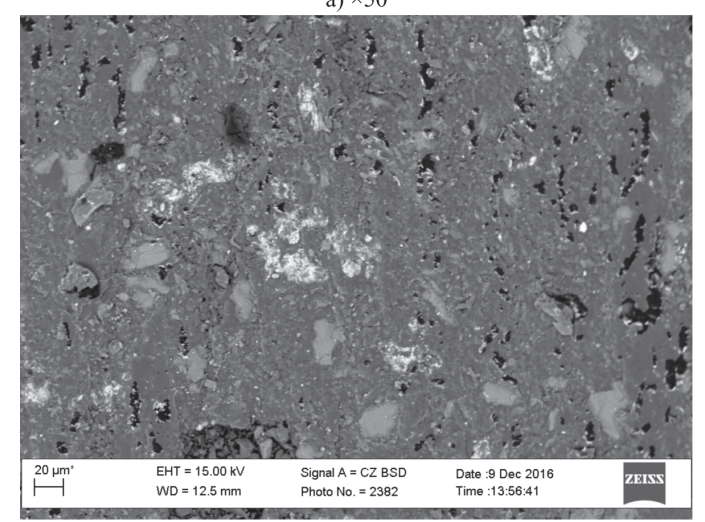

c) $\times 250$

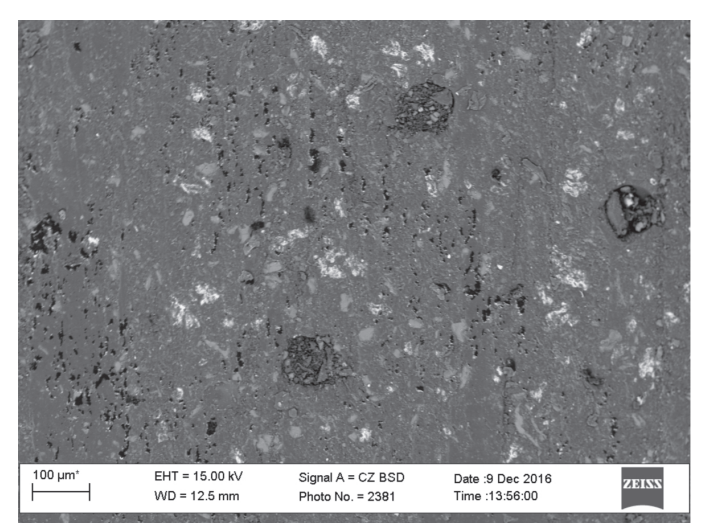

b) $\times 100$

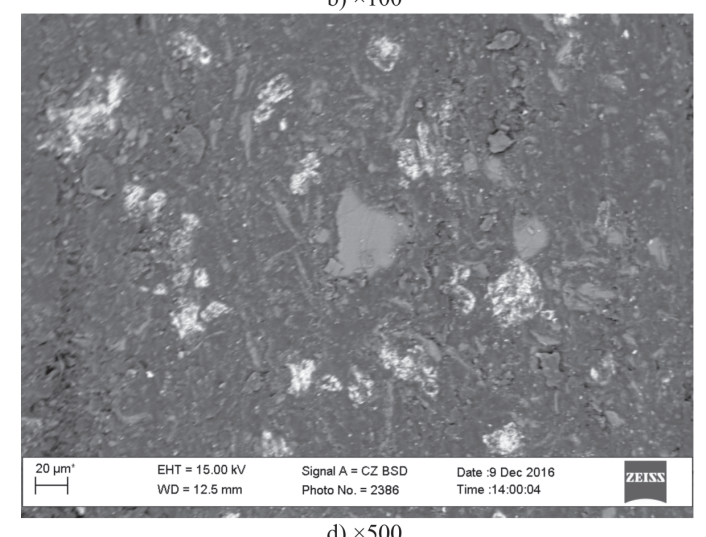

d) $\times 500$

Fig. 6 The microstructure of the friction surface of the specimen after testing in a viscous environment (lubricant), obtained by means of a scanning electron microscope in the range of magnification $\times 50-\times 500$ times

the change of the curves of dependence of indexes, shown in Fig. 1 (curve 3, 4) and Table 1.

Each of the surfaces, forming a friction pair, is formed as a result of the separate contact interaction of the microirregularities of the working pair. Therefore, to determine their nature, a local X-ray spectral analysis of the chemical composition of various spectra of the sections of individual surfaces of the friction of composite was conducted. This investigation can be done as a spot testing in a given point of the friction surface, and in a given direction. As a result, profilograms of planes of the selected parts of the friction surface of the initial specimen and specimen after the test without lubricant in a wide spectrum were obtained (Figs. 7, 8). The surface of friction of the composite, which was tested in the lubricating environment (see Fig. 9), was also studied in a wide spectrum and at given points. The above results as weight and atomic content of the elements are given in the tables (Table 2-4 respectively). To reduce the error of the experiment, the same size of the friction surfaces of the initial specimen, the specimen after the test without lubrication and with the lubricant, which were $(320 \times 460) \mu \mathrm{m}$, were chosen.
Analyzing the experimental results of the elemental composition of a wide spectrum of the above specimens, it is stated the following. The carbon is characterized by high weight content in all investigated spectra: $73.03 \%$ (Table 2), $62.88 \%$ (Table 3 ) and $68.22 \%$ (Table 4). This confirms that carbon is a part of the CM matrix. The oxygen is the following by the weight content: $22.39 \%, 20.72 \%$, and $13.28 \%$ respectively. This indicates the presence of this element, both in the matrix, and in the fillers - in oxide of bivalent copper and in mica-muscovite. This assumption is confirmed by the fact that the copper atom in $\mathrm{CuO}$ is surrounded by four oxygen atoms and has a distorted flat configuration, and the chemical compounds $\mathrm{SiO}_{2}, \mathrm{Al}_{2} \mathrm{O}_{3}, \mathrm{~K}_{2} \mathrm{O}$ and $\mathrm{Fe}_{2} \mathrm{O}_{3}$ are the main components of the micromica. The location of the elements aluminum, silicon and potassium on all three broad spectra of the investigated specimens reflects their presence directly in the area of friction and confirms the participation of the filler of mica in the process of friction. Let us note the presence of iron and copper in the investigated sections of the composites tested in dry friction and with lubricant material. It should also be noted, that there is no copper element on the surface of the initial specimen of CM. It can be 


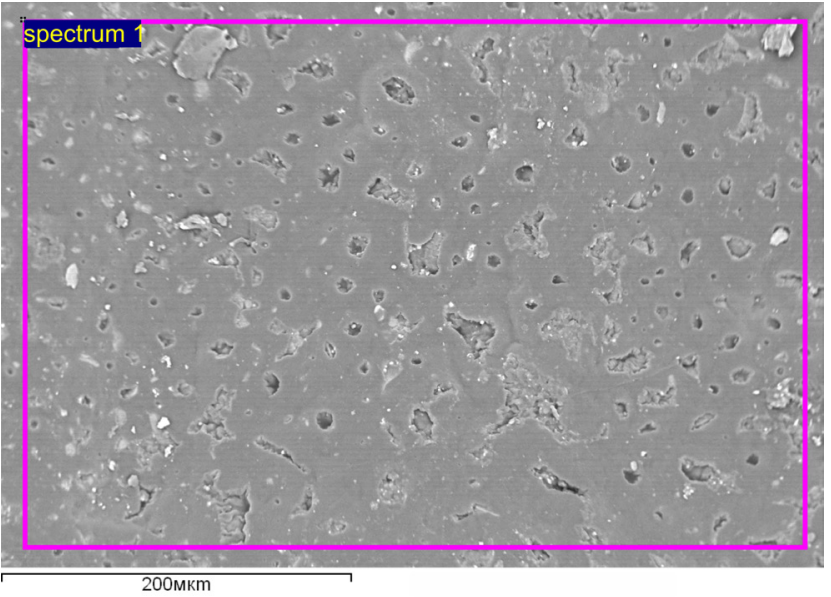

Fig. 7 The microstructure of the friction surface of the initial specimen

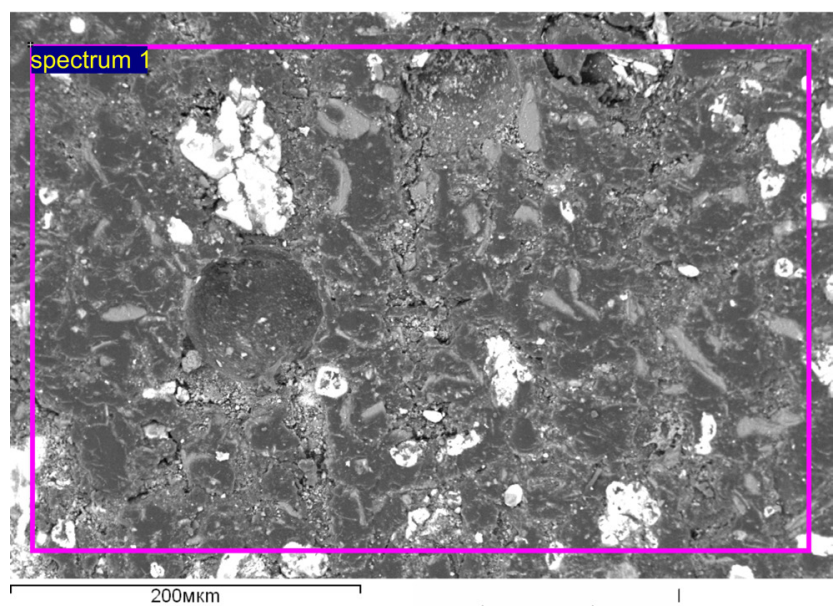

Fig. 8 The microstructure of the surface of the specimen, which was tested with dry friction

Table 2 Chemical composition of the surface of initial CM

\begin{tabular}{lcc}
\hline \multirow{2}{*}{ Element } & \multicolumn{2}{c}{ Spectrum 1 } \\
& Weight, \% & Atom, \% \\
\hline $\mathrm{C}$ & 73.03 & 79.62 \\
$\mathrm{O}$ & 22.39 & 18.33 \\
$\mathrm{Al}$ & 1.46 & 0.71 \\
$\mathrm{Si}$ & 2.26 & 1.05 \\
$\mathrm{~K}$ & 0.86 & 0.29 \\
Total & \multicolumn{2}{c}{100.00} \\
\hline
\end{tabular}

stated, that the $\mathrm{CuO}$ filler is located in the near-surface layer, and does not enter the frictional contact at the initial stage of the running-in of the material. Accordingly, the iron atoms can simultaneously be a component of $\mathrm{Fe}_{2} \mathrm{O}_{3}$, which is a part of the mica, as was mentioned above, and be the particles of counterbody, transferred to the composite due to the friction. On the surface of the specimen, which was tested in a lubricating environment, the content of gold was observed, which content by the atoms was $0.57 \%$. Since none of the

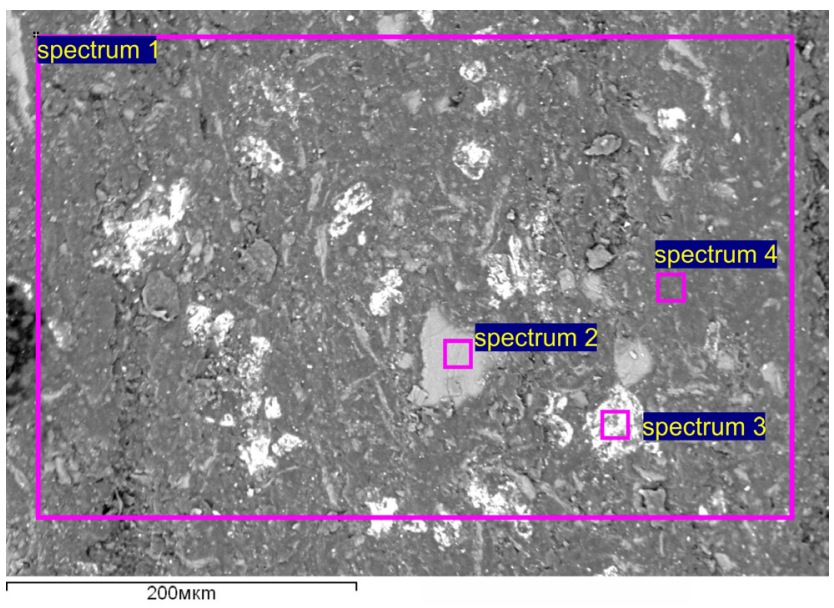

Fig. 9 The microstructure of the friction surface of the specimen after a test in the lubricant

Table 3 The chemical composition of the surface of the CM, which was tested with dry friction.

\begin{tabular}{lcc}
\hline \multirow{2}{*}{ Element } & \multicolumn{2}{c}{ Spectrum 1 } \\
& Weight \% & Atom \% \\
\hline $\mathrm{C}$ & 62.88 & 75.69 \\
$\mathrm{O}$ & 20.72 & 18.72 \\
$\mathrm{Al}$ & 2.13 & 1.14 \\
$\mathrm{Si}$ & 2.97 & 1.53 \\
$\mathrm{Cl}$ & 0.30 & 0.12 \\
$\mathrm{~K}$ & 1.30 & 0.48 \\
$\mathrm{Fe}$ & 3.43 & 0.89 \\
$\mathrm{Cu}$ & 6.27 & 1.43 \\
Total & \multicolumn{2}{c}{100.00} \\
\hline
\end{tabular}

components of the matrix includes this element and it is not included in the list of "other soluble salts" indicated by the manufacturer of the micromica [21], it is evident that gold was introduced into the investigated spectrum due to the application of the electroconductive layer on the surface of the composite. The change in the ratio of the atoms, which form part of the composite, was further analyzed in the transition from the data processing of investigation of the initial $\mathrm{CM}$ to the analysis of microsurface of the specimens tested in dry friction and lubricating material. The data indicate that each point of the friction region is formed as a result of a separate contact of the particles of $\mathrm{CM}$ with the material of the counterbody on the contact surface. This process is accompanied by the transfer of particles of composite as a result of seizure, scoring, wear. This additionally confirms the above mentioned assumptions.

The spectra of the separate structural elements of the surface, which are shown in Fig. 9, were investigated for a detailed analysis of the composition of the composite material after the test in the lubricant. In addition 
Table 4 The chemical composition of the surface of CM, that was tested in lubricant

\begin{tabular}{|c|c|c|c|c|c|c|c|c|}
\hline \multirow[b]{2}{*}{ Element } & \multicolumn{2}{|c|}{ Spectrum 1} & \multicolumn{2}{|c|}{ Spectrum 2} & \multicolumn{2}{|c|}{ Spectrum 3} & \multicolumn{2}{|c|}{ Spectrum 4} \\
\hline & $\begin{array}{c}\text { Weight } \\
\%\end{array}$ & $\begin{array}{c}\text { Atom } \\
\%\end{array}$ & $\begin{array}{c}\text { Weight } \\
\%\end{array}$ & $\begin{array}{c}\text { Atom } \\
\%\end{array}$ & $\begin{array}{c}\text { Weight } \\
\%\end{array}$ & $\begin{array}{c}\text { Atom } \\
\%\end{array}$ & $\begin{array}{c}\text { Weight } \\
\%\end{array}$ & $\begin{array}{c}\text { Atom } \\
\%\end{array}$ \\
\hline $\mathrm{C}$ & 68.22 & 83.14 & 19.80 & 31.93 & 49.76 & 74.88 & 74.49 & 80.02 \\
\hline $\mathrm{O}$ & 13.28 & 12.15 & 29.79 & 36.07 & 12.81 & 14.47 & 24.00 & 19.35 \\
\hline $\mathrm{Na}$ & - & - & 0.47 & 0.40 & - & - & - & - \\
\hline Al & 1.84 & 1.00 & 14.88 & 10.68 & - & - & 0.32 & 0.15 \\
\hline $\mathrm{Si}$ & 2.55 & 1.33 & 21.35 & 14.73 & - & - & 0.45 & 0.21 \\
\hline $\mathrm{Cl}$ & 0.50 & 0.21 & - & - & - & - & 0.74 & 0.27 \\
\hline K & 1.26 & 0.47 & 9.63 & 4.77 & - & - & - & - \\
\hline $\mathrm{Ca}$ & 0.43 & 0.16 & - & - & - & - & - & - \\
\hline $\mathrm{Fe}$ & 0.71 & 0.18 & 4.08 & 1.42 & - & - & - & - \\
\hline $\mathrm{Cu}$ & 3.45 & 0.79 & - & - & 37.43 & 10.65 & 0.00 & 0.00 \\
\hline $\mathrm{Au}$ & 7.76 & 0.57 & - & - & - & - & - & - \\
\hline Total & \multicolumn{2}{|c|}{100.00} & \multicolumn{2}{|c|}{100.00} & \multicolumn{2}{|c|}{100.00} & \multicolumn{2}{|c|}{100.00} \\
\hline
\end{tabular}

to the above-described broad spectrum covering the entire surface of the study, three more regions of friction (spectra 2-4) were selected. Spectrum 2 is characterized by the following weight content of the main elements: carbon $-19.80 \%$, oxygen $-29.79 \%$, aluminum $-14.88 \%$, silicon $-21.35 \%$ and potassium $-9.63 \%$ of the total content with insignificant content of sodium and iron. According to the standard, this combination of elements corresponds to the chemical composition of mica-muscovite $\mathrm{KAl}_{2}\left[(\mathrm{OH}, \mathrm{F})_{2} \mathrm{AlSi}_{3} \mathrm{O}_{10}\right]$, which was used in the form of powder as a disperse filler in the matrix.

The presence of sodium atoms is due to the crystal-chemical characteristic of mica. The three-layered packages are placed in basis structures of the mica; they consist of two tetrahedral layers $\left[\mathrm{AlSi}_{3} \mathrm{O}_{10}\right]$, and octahedral layer, which consist of cations $\mathrm{Mg}^{2+}, \mathrm{Fe}^{2+}$ and $\mathrm{Al}^{+}$, is between them. Two of six atoms of oxygen of octahedra are replaced by hydroxyl groups $(\mathrm{OH})$ or fluorine, and the packages are bound to a continuous structure through the ions of $\mathrm{K}^{+}$or $\mathrm{Na}^{+}$.

At the local X-ray spectral analysis of the chemical composition of the surface to which spectrum 3 corresponds (Table 4), the following weight content of the chemical elements is determined: carbon $-49.76 \%$, oxygen $-12.81 \%$, copper $-37.43 \%$. This indicates that the structural elements of surface of CM are microdispersed particles of bivalent copper oxide. In this case, we can observe a significant content of carbon atoms, which allows asserting the placement of this filler in the surface layer of CM after testing in the lubricant.

Spectrum 4 is characterized by the following content of atoms of chemical elements in the weight ratio: carbon $-74.49 \%$, oxygen $-24.00 \%$, aluminum $-0.32 \%$, silicon
$-0.45 \%$, and chlorine $-0.74 \%$. This indicates that the selected spectrum corresponds to the matrix of the composite. The insignificant presence of aluminum, silicon and chlorine atoms, which are in the chemical composition of the mica, indicates the transfer of components of the compound due to the individual contact interaction of the microirregularities of the working pair. It should be noted, that the processing of the data of the spectra of the $\mathrm{X}$-ray spectral analysis of the chemical composition of the $\mathrm{CM}$ confirms the initial assumption about the location of the elements on the specimen surface, in accordance with the color of the elements of this surface.

To confirm the results of the investigation, obtained by processing the data of the microstructure and chemical composition of the tested surface of the specimen of CM, which was tested in the lubricant, an energy dispersive X-ray analysis of the friction surface of CM was performed (Fig. 10).

The investigated specimen was irradiated with high-energy electrons $(1-20 \mathrm{keV})$, resulting the appearance of the emission of X-rays from its surface. The X-ray generation is the result of an inelastic interaction between electrons and specimen. According to the results of the energy-dispersive $\mathrm{X}$-ray analysis, the following can be noted. The qualitative structure of the elements on the spectra corresponds to the quantitative structure of these chemical elements given in Table. 4. The nature of the placement of elements with repetition indicates the absence of modular pollution, and therefore, the veracity of the experiment. Taking into account, that the $90 \%$ of groundmasses of photons are in a layer with thickness up to 3 microns, it can be asserted that both fillers are located in the surface layer of CM and are directly involved in the friction process. 


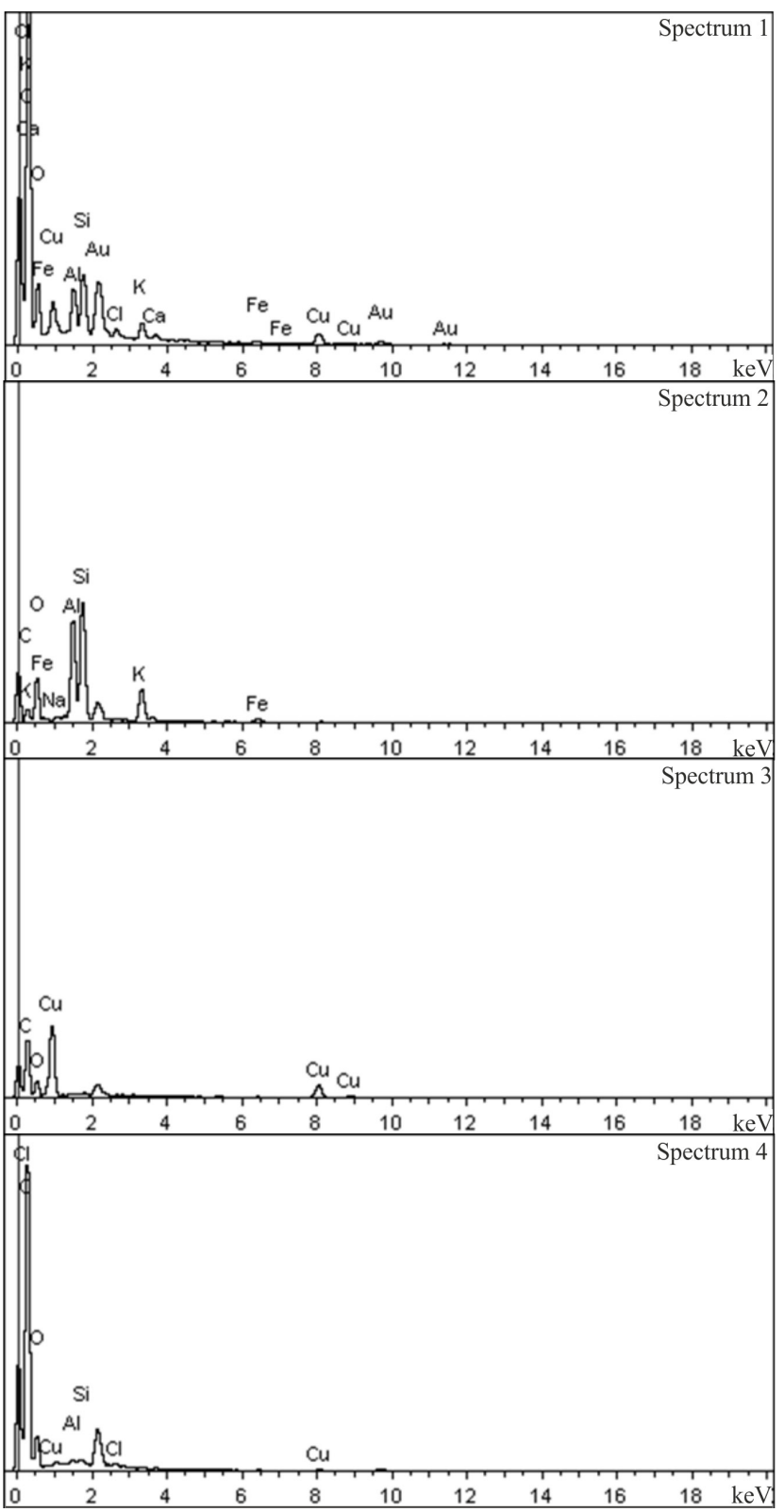

Fig. 10 The spectra of the energy of the energy dispersive X-ray analysis of the surface of the specimen after a test in the lubricant

Obviously, the above-mentioned results of the investigation of the surface microstructure and its elemental composition do not fully reflect the position of the elements on the area of CM. For the analysis of the placement of a particular element on the surface, the analysis of the specimens was also conducted in phase contrast mode, when not secondary electrons are recorded, but backscattered electrons (Fig. 11). The images were generated by converting the number of X-ray photons of a specific energy, detected at each point, into the brightness value for the pixel on the screen or into a digital image with a unique color for each element.
Analyzing the obtained results of the chemical elements distribution on the surface of specimen of CM, we can state the following. The distribution of elements such as oxygen, aluminum, silicon and potassium coincides with the placement of mica particles on the image of composite microstructure. The distribution of the copper element reflects the placement of disperse filler's particles $\mathrm{CuO}$. This confirms the previous conclusions about the evenly location of mica and $\mathrm{CuO}$ particles in a compound and their participation in the friction process. It should also be noted that on the distribution map, the element iron is evenly located on the surface of CM. Firstly, this also confirms the location of the mica particles evenly throughout the friction surface, and secondly, it confirms the presence of counterbody on the friction surface.

So, the results of the analysis of the friction surface of $\mathrm{CM}$ in the mode of phase contrast are fully confirmed by previous investigations.

The data processing of the experiment showed that the tribological properties are influenced by the degree of surface roughness, adhesion in friction, seizure, scoring, the
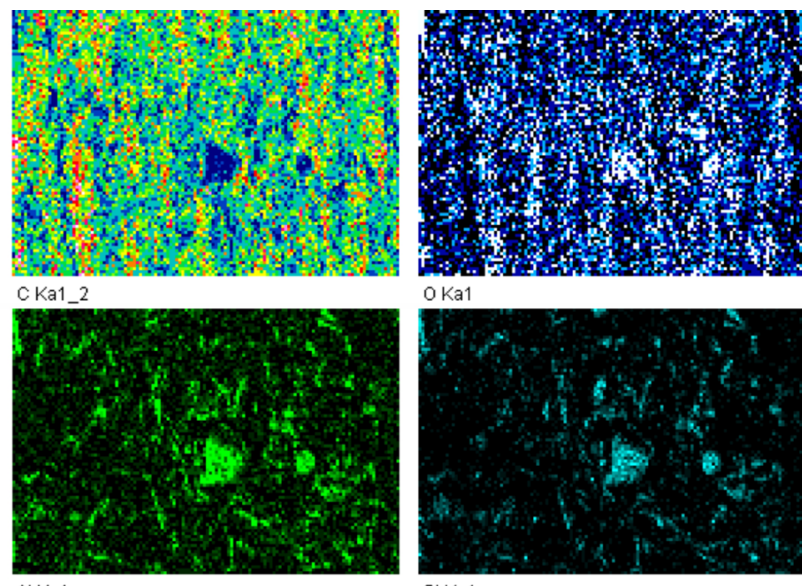

Al Ka1

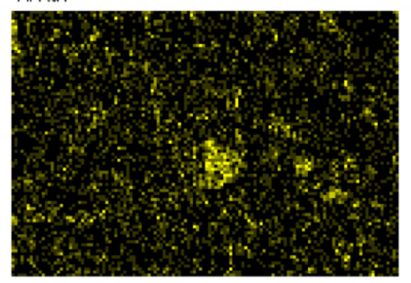

SiKa1
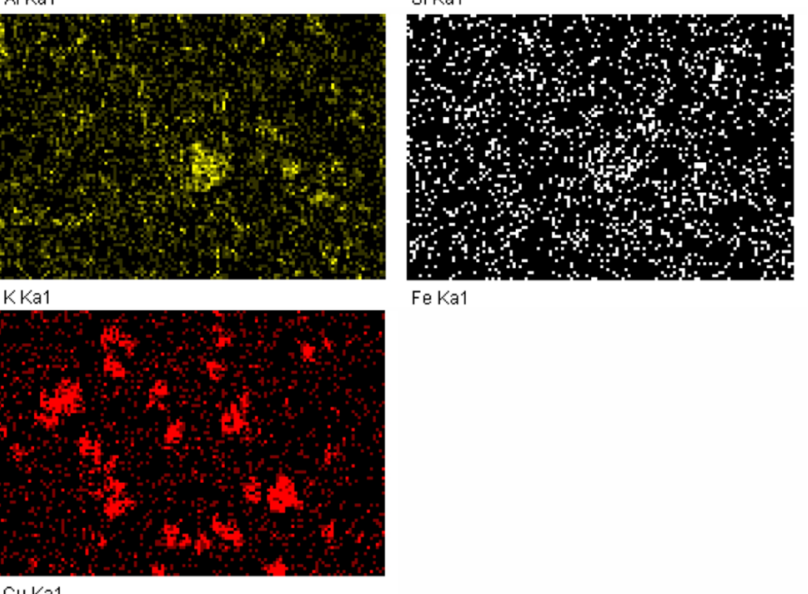

Fe Ka1

Fig. 11 The distribution of elements on the surface of the composite, which was tested in the lubricant 
transfer of counterbody particles on the composite, the presence and placement of antifriction fillers, heat removal from the friction region, composition of the material, technology of its obtaining and test conditions. As a result of the X-ray spectral analysis of the chemical composition of the friction surface of the CM, the content of the elements and the location of disperse fillers on the surface layer of the composite material was explained.

\section{Conclusions}

The tribological properties of antifriction materials based on a compound with two disperse fillers: mica and $\mathrm{CuO}$, were investigated. Analyzing the obtained results of the test of developed CM with dry friction and in the lubricating environment, one can note the following.

It is determined, that the friction coefficient depends on the composition of the composite, the technology of its obtaining and the conditions of the testing. It is proved, that the contact temperature in the contact area during the friction in the lubricant remains stable and is $T=293-295 \mathrm{~K}$. The material, tested in lubrication, differs with the low indexes of wear rate and friction coefficient $-I_{m}=0.25-0.30 \mathrm{mg} / \mathrm{km}, f=0.03-0.04$. The running-in distance under these conditions is $L=1500$ $2000 \mathrm{~m}$. This is due to the fact that there is an increase of the strength of CM, when inserting disperse fillers. This, in its turn, helps to reduce the coefficient of friction and increase the wear resistance of CM.

As a result of the study of the friction surface of CM by optical microscopy method, data obtained at the first stage of the experiment was confirmed. It was determined, that the increase of friction coefficient in the path of running-in $L=6000-10,000 \mathrm{~m}$ is the result of the adhesion in friction and transfer of material of CM. It was stated, that the wear resistance of the composite ingredients, the degree of surface roughness, adhesion in friction, seizure, scoring, the presence and placement of antifriction fillers influence on the tribological properties. The phase heterogeneity of the CM system has been detected, which contributes to faster running-in of the specimen. It is confirmed that the wear rate at dry friction is higher than with the lubricant. It was analyzed, that the particles of the filler are evenly located on the friction surface, and it can be asserted, that they are directly involved in the friction contact.

Using the method of scanning electron microscopy, an analysis of the microstructure of friction surface was conducted and the elemental composition was determined. According to the results of the study it was determined, that the spectrum 2 is characterized by the following weight content of the main elements: carbon $19.80 \%$, oxygen $-29.79 \%$, aluminum $-14.88 \%$, silicon $-21.35 \%$, and potassium $-9.63 \%$ of total composition with an insignificant content of sodium and iron. This indicates the placement of mica particles in the composite. Spectrum 3 corresponds to the next weight content of chemical elements: carbon $-49.76 \%$, oxygen $-12.81 \%$, copper $-37.43 \%$. The presence of these atoms identifies the structural elements of the surface of CM, identical to those selected, as the microdispersed particles of oxide of bivalent copper. It was found that copper (II) oxide is located in the near-surface layer, and does not enter the friction process at the initial stage of the running-in of material. Spectrum 4 differs by the following content of chemical elements at a weight ratio: carbon (74.49\%), oxygen $(24.00 \%)$, aluminum $(0.32 \%)$, silicon $(0.45 \%)$ and chlorine $(0.74 \%)$. This indicates that the selected spectrum corresponds to the matrix of the composite with small particles of the transferred material. It is confirmed that the system is heterogeneous, dispersed fillers are evenly distributed in the volume of the matrix. The existing processes of destruction and separation of material from the surface of CM are not placed directly around the dispersed particles, indicating their strong bonding with the macromolecules of the matrix in accordance with the molecular theory of adhesion. It is determined, that each of the investigated friction surfaces is formed due to the separate contact interaction of the microirregularities of the working pair, which is confirmed by a change in the ratio of atoms on the surface before and after the test, and with the presence of iron particles $(0.71 \%)$.

The results of the X-ray spectral analysis of the chemical composition of the CM confirm the initial assumption about the location of the elements on the specimen surface, in accordance with the color of the microrelief objects. It is confirmed, that the qualitative composition of the spectra corresponds to quantitative analysis of chemical elements. The data of the experiments is also confirmed by investigation of the surface in the mode of phase contrast. The distribution of such elements as oxygen, aluminum, silicon and potassium coincides with the placement of particles of the micromica filler on the picture of microstructure of the friction surface of the specimen. The image of the copper element reflects the placement of disperse particles of the $\mathrm{CuO}$ filler. 


\section{References}

[1] Selvaraju, S., Ilaiyavel, S. "Applications of composites in marine industry", Journal of Engineering Research and Studies, 2, pp. 89-11, 2011.

[2] Kindrachuk, M., Shevchenko, A., Kryzhanovskyi, A. "Improvement of the quality of TiC-Co system plasma coating by laser treatment", Aviation, 20(4), pp. 155-159, 2016. https://doi.org/10.3846/16487788.2016.1227551

[3] Kindrachuk, M. V., Dushek, Y. Y., Luchka, M. V. "The local character of the stress-strained state of a composite loaded by friction forces", Poroshkovaya Metallurgiya, (9-10), pp. 56-61, 1994.

[4] Kindrachuk, M. V., Dushek, Y. Y., Luchka, M. V., Gladchenko, A. N. "Evolution of the structure and properties of eutectic coatings during friction", Powder Metallurgy and Metal Ceramics, 34(5-6), pp. 321-326, 1995.

https://doi.org/10.1007/BF00560139

[5] Pokhmurs'kyi, V. I., Rats'ka, N. B., Vasyliv, K. B., Vynar, V. A. "Improvement in the Wear Resistance of the $\mathrm{Nb}-\mathrm{Ti}$ Alloy System by Using Thermodiffusion Oxidation", Strength of Materials, 48(6), pp. 740-746, 2016.

https://oi.org/10.1007/s11223-017-9820-5

[6] Panin, S. V., Maruschak, P. O., Vlasov, I. V., Moiseenko, D. D., Berto, F., Vinogradov, A. "Effect of Temperature-Force Factors and Concentrator Shape on Impact Fracture Mechanisms of 17Mn1Si Steel", Advances in Materials Science and Engineering, 2017, pp. 1-12, 2017.

https://doi.org/10.1155/2017/9867217

[7] Buketov, A., Sapronov, O., Brailo, M., Aleksenko, V. "Influence of the Ultrasonic Treatment on the Mechanical and Thermal Properties of Epoxy Nanocomposites", Materials Science, 49(5), pp. 696-702, 2014.

https://doi.org/10.1007/s11003-014-9664-0

[8] Buketov, A. V., Sapronov, A. A., Buketova, N. N., Brailo, M. V., Marushak, P. O., Panin, S. V., Amelin, M. Y. "Impact toughness of nanocomposite materials filled with fullerene C60 particles", Composites: Mechanics, Computations, Applications: An International Journal, 9(2), pp. 141-161, 2018. https://doi.org/10.1615/CompMechComputApplIntJ.v9.i2.30

[9] Buketov, A. V., Brailo, M. V., Kobel'nyk, O. S., Akimov, O. V. "Tribological properties of the epoxycomposites filled with dispersed particles and thermoplastics", Materials Science, 52(1), pp. 25-32, 2016. https://doi.org/10.1007/s11003-016-9922-4

[10] Duleba, B., Dulebová, L., Spišák, E. "Simulation and evaluation of carbon/epoxy composite systems using FEM and tensile test", Procedia Engineering, 96, pp. 70-74, 2014. https://doi.org/10.1016/j.proeng.2014.12.099

[11] Datsyuk, V., Trotsenko, S., Reich, S. "Carbon-nanotubepolymer nanofibers with high thermal conductivity", Carbon, 52, pp. 605-608, 2013

https://doi.org/10.1016/j.carbon.2012.09.045

[12] Brusentseva, T. A., Filippov, A. A., Fomin, V. M., Smirnov, S. V., Veretennikova, I. A. "Modification of epoxy resin with silica nanoparticles and process engineering of composites based on them", Mechanics of Composite Materials, 51(4), pp. 531-538, 2015.

https://doi.org/10.1007/s11029-015-9523-6
[13] Agrawal, S., Singh, K. K., Sarkar, P. K. "A comparative study of wear and friction characteristics of glass fibre reinforced epoxy resin, sliding under dry, oil-lubricated and inert gas environments", Tribology International, 96, pp. 217-224, 2016. https://doi.org/10.1016/j.triboint.2015.12.033

[14] Şahin, Y., De Baets, P. "Friction and Wear Behavior of Carbon Fabric-Reinforced Epoxy Composites", JOM, 69(12), pp. 2443-2447, 2017 https://doi.org/10.1007/s11837-017-2273-2

[15] He, S., Petkovich, N. D., Liu, K., Qian, Y., Macosko, C. W., Stein, A. "Unsaturated polyester resin toughening with very low loadings of GO derivatives", Polymer, 110, pp. 149-157, 2017. https://doi.org/10.1016/j.polymer.2016.12.057

[16] Lin, J., Zhong, B., Jia, Z., Hu, D., Ding, Y., Luo, Y., Jia, D. "In-situ fabrication of halloysite nanotubes/silica nano hybrid and its application in unsaturated polyester resin", Applied Surface Science, 407, pp. 130-136, 2017. https://doi.org/10.1016/j.apsusc.2017.02.149

[17] Lavoratti, A., Scienza, L. C., Zattera, A. J. "Dynamicmechanical and thermomechanical properties of cellulose nanofiber/polyester resin composites", Carbohydrate polymers, 136, pp. 955-963, 2016 https://doi.org/10.1016/j.carbpol.2015.10.008

[18] Buketov, A. V., Sapronov, O. O., Brailo, M. V. "Investigation of the Physico-Mechanical and Thermophysical Properties of Epoxy Composites with a Two-Component Bidisperse Filler", Strength of Materials, 46(5), pp. 717-723, 2014. https://doi.org/10.1007/s11223-014-9605-z

[19] Buketov, A. V., Brailo, N. V., Maruschak, P. O., Akimov, A. V., Kobelnik, O. S., Panin, S. V. "Tribological properties of epoxy composite materials for marine and river transport", In: Advanced Materials with Hierarchical Structure for New Technologies and Reliable Structures 2016 AIP Conference Proceeding, Tomsk, Russia, 2016, pp. 020020-1-020020-5.

https://doi.org/10.1063/1.4966313

[20] Brailo, M., Buketov, A., Yakushchenko, S., Sapronov, O., Vynar, V., Kobelnik, O. "The Investigation of Tribological Properties of Epoxy-Polyether Composite Materials for Using in the Friction Units of Means of Sea Transport", Materials Performance and Characterization, 7(1), pp. 275-299, 2018. https://doi.org/10.1520/MPC20170161

[21] "Микрослюда. Микрослюда фракционированная серии «Стандарт»" (Technical data sheet. Micromica. Fractionated micromica "Standard" series), (in Russian) [online] Available at: http://impexinvest.com.ua/p_img/mikrosluda_std.pdf [Accessed: 17 September May 2018]

[22] Scrivener, K. L. "Backscattered electron imaging of cementitious microstructures: understanding and quantification", Cement and Concrete Composites, 26(8), pp. 935-945, 2014. https://doi.org/10.1016/j.cemconcomp.2004.02.029 